\begin{tabular}{|l|l|l|l|l|l|}
\hline Senckenbergiana lethaea & 82 & (1) & $207-222$ & 13 Fig. & Frankfurt am Main, 30.6.2002 \\
\hline
\end{tabular}

Concepts of Functional, Engineering and Constructional Morphology*

\title{
Biomechanical investigations on the Skulls of Reptiles and Mammals
}

\author{
With 13 Figures
}

Holger Preuschoft \& UlRich WitZeL

\begin{abstract}
The skulls of reptiles and mammals can be loaded mechanically in three ways: the weight of the head acting downward, perhaps reinforced by a prey or bunch of food lifted from the ground or water surface; by forces acting in the plane of the tooth row, created by movements of the prey in relation to the head or by a movement of the head in relation to a fixed food object; and by the adduction of the mandible, which leads to reaction forces in the skull. While the former two evoke stress patterns comparable to that in a beam which is supported at its rear end (by the occipital condyle(s) and the neck muscles), the latter evoke stress patterns comparable to a beam supported at both ends. Its anterior bearing are the teeth which transmit a reaction force from the seized prey, the adductor muscles of the mandible move the intermediate part of the skull downward, and the posterior bearing is provided by the mandibular joint.

Three-dimensional FEM-analysis of the flow of stresses within solid, homogeneous bodies under loads like those described above have been made. As a result, the stress flows have been found to correspond closely to the arrangements of bony material in the akinetic skulls of Crocodiles, Lacertilia, Sphenodon. Except crocodiles and chelonians, reptilian skulls often show large gaps between the load-bearing plates and rods. These gaps correspond to little stressed areas between the stress-bearing parts. One of the stressbearing rods is the small braincase. In long, slender jaws like those in crocodiles the stresses are concentrated on the periphery, with more or less stress-free areas in the center of the cross sections.

In many mammals (shrews, primates including Homo), however, the very large bony nasal capsule and braincase lead to a distribution of the forces over large areas like in thin-walled shell structures, which are strong enough to sustain the existing forces, whithout reinforcing superstructures. Even the zygomatic arch can be dispensible.

The decisive a priori factors which determine the development of either a rod- or a shell-like structure in a FEM model are

1st the relative shape and length of the toothrow and its position in relation to the posterior part of the skull, especially the braincase, and 2nd the size of the nasal capsule and the braincase.

We conclude that the exact form of the skull in both classes of animals is determined by 1 st the shape and length of the jaws and 2nd by the space requirements of the olfactory and the optical sense organs, and the braincase. The second factor is an expression of the overall evolutionary level. The literature contains plausible biological arguments to explain the high selective influence of lifestyle characteristics on the first factor. These arguments usually cover also the position of the eye openings, the nasal opening and the relative height and length of the whole skull. If these factors are given, the exact morpholgy of the bony structure turns out to correspond completely to the pattern of stresses, and no other reasons behind skull shape must be searched.

The arrangement of the muscles seems to follow in all cases the principle to distribute the force created at the origines on a large surface or on many individual bony elements.
\end{abstract}

Key words: reptilian skull, mammalian skull, three-dimensional FEM-analysis, biostatics, load-bearing structure, bite force, joint force, occipital condyle

*) Special issue of Senckenbergiana lethaea, edited by Michael Gudo, Mathias Gutmann \& Joachim Scholz

Authors' addresses: Prof. Dr. HOLger PreusChOFT, Formerly Subdepartment Functional Morphology, Anatomical Institute, Medical Faculty Ruhr-Universität Bochum MA 01/436, 44780 Bochum, Germany, e-mail: Holger.Preuschoft@rz.ruhr-uni-bochum.de; Prof. Dr. ULRICH WITZEL, Forschungsgebiet Biomechanik, Fakultät für Maschinenbau, Ruhr-Universität Bochum JB 01/Nord, 44780 Bochum, Germany, e-mail:

Ulrich.Witzel@rz.ruhr-uni-bochum.de. 


\section{Introduction}

Most considerations of skull development are focussed on the phylogenetic origin of the individual bony elements that constitute the skull (e.g. GREGORY, 1929/63; VERSLUYS 1936; ROMER \& FRICK 1966, ROMER \& PARSONS 1991, CARROLL, 1969, JORDANSKI, 1973, STARCK, 1979a, b). Emphasis usually is put on the role of the bony elements as armour on the anterior part of the body in fish-like animals and water-living amphibians on one side, and the necessity to reduce mass of the head after the change to a terrestrial lifestyle. In land-living animals, the weight of the head must be carried on the neck with minimal energy expenditure, and as soon as a mobile, probably long neck has evolved, its mass moments of inertia must be kept low, in order to permit rapid snapping. Both requirements favour a reduction of the bone mass and perhaps also of the number of bony elements. The fenestrations of the reptilian and mammalian skulls are seen under this viewpoint, but the action of the inflated muscles is also taken into consideration. This, however, is not exactly in line with what happens, if bone is exposed to the forces exerted by muscles: Its usual response is increased bone deposition, not disappearance. The idea that bone develops where mechanical stress comes into action was introduced repeatedly, but never persued in detail. This may be due to the fact that the complex, three-dimensional form of the skull is very difficult to analyse satisfactorily by simple statical approaches.

In former studies of one of the authors (PREUSCHOFT et al., 1985, 1986), the coincidence between the mechanical properties of the upper jaws and the mechanical stresses in longsnouted mammals has been demonstrated. The walls of the elongate nasal (or, more precisely, the suprapalatal) cavity, the palate and the premaxilla plus maxilla, together with the jugal or zygomatic elements in front of the eye-holes seem to represent a modified tube, adapted to sustain the stresses derived from biting and transmit them onto the posterior part of the skull, where the circle of forces is closed by the mandibular adductor muscles. This holds true more or less for longsnouted mammals and in essential also for crocodiles. STROTDREES (1998) examined the chondrocranium of a marsupial, Monodelphis, at the time shortly after birth. The attachment of the poach young to the tits of the mother clearly leads to defined stress patterns in the skull: bending moments in two planes are dominating. The chondrocranium in marsupials is rather strong in comparison to the none-loaded eutherian crania of comparable age, and turned out to be well suited to sustain the stresses. The earliest appearing bone cores are located at exactly those places, where the stresses assume their highest values. This is in accordance with well-known situations in the post-cranial skeleton, as decribed by KUMMER in BENNINGHOFF's textbook 1980, or by SCHLEBERGER (1990, p. 73). A study of RossmanN, Witzel \& WELMAN (2001), on the fossil long-snouted reptilian Proterosuchus with a three-dimensional FEM model documented the channelling of stress flows along the structural elements of the bony skull. Finally, our joined efforts to identify the stress flow in the skulls of primates (Homo, Gorilla, Pan: Witzel \& Preuschoft, 1999, 2002; PREUSCHOFT et al. 2002; PREUSChOFT \& WITZEL in press) yielded ample experience on stress distribution in skulls and in the factors that exert influence on the stress pattern and thus on the arrangement of bone substance in the skull. On this basis, it seemed attractive and rewarding to look at principle characteristics of skull construction and its differences among classes and orders of vertebrates.

\section{Material}

All vertebrates have in common biting as the primary function of the jaws, which evokes great stresses in the skull. In addition, the weight of the head needs to be kept in balance on the neck, and in movements its moment of inertia must be overcome. This is accomplished by the activity of the neck muscles, which insert into the occiput.

Before going into details of skull morphology, some basic mechanical conditions need to be considered. These can best and most evidently be explained for the crocodile as an example, because its anatomy is as well known as its raptorious habits.

In many living reptiles, skull morphology is influenced to a smaller or larger degree by the mobility of the skull. This feature is usually seen as a means to permit wider gape (e.g. STARCK, 1979 a, VERSLUYS 1936). We feel, however, that the effect on gape is not as pronounced (because the sine of small angles does not change much) as the effect on the stresses that occur in the jaws especially in rapid snapping. If the teeth hit in rapid snapping a hard bone, they are stopped during a very short time interval. Negative acceleration, and therefore the forces in the teeth and jaws assume very high values. If the stopping of the upper and lower jaws is slowed down by elastic deformation of the kinetic skull from 30 milliseconds to 60 milliseconds, the forces are reduced to one half! A marked mobility can be found, aside from snakes, in the genus Varanus.. This mobility of the skull makes varanid skulls unsuitable examples for the simple static approach used here. Nevertheless, a comparison between the carnivorous $V$. salvator and the largely durophagous $V$. niloticus illustrates impressively the dependence of skull strength upon the hardness of prefered food. Most of what is detailed below holds true for varanids as well.

In adult Iguanids (Iguana, Tupinambis used as examples) or the diapsid Sphenodon, skull mobility is, though incompletely known, only moderate and seems restricted to younger individuals, while old specimens seem to loose it completely by fusion of the quadrate bone to the skull (in detail see HOFER 1960 for Tupinambis). Therefore, the skulls of the mentioned genera seem to be good examples for an analysis of the akinetic reptile skulls. From a large number of systematically varied FE-models we learned that stress flows are to a great extent opportunistic. That means, a priori existing structural elements are used by stress flows. Therefore the possibility cannot be ruled out, that in the genera mentioned the shapes of the skulls were determined by the needs of skull kinetics and just maintained after the loss of this function.

So we decided to take into account the skull shapes of two saurischian carnosaurs, Allosurus and Albertosaurus. These animals are of sizes comparable to the largest crocodiles and so the possible allometric effects of size will not mislead conclusions. Other sauropods (e. g. Camarasaurus and Brachiosaurus could easily be interpreted by the same method, but are not included into the present analysis. 


\section{Methods}

Our first approach is made by simple application of wellknown and well-established knowledge of engineering mechanics to biological structures, in this case the skulls. As a control of deductions, or as a confirmation of details, the threedimensional FEM program ANSYS 5.5.3 has been used. This program yielded the decisive information about the distribution of those stresses, which are acting on a vertebrate skull in biting. We investigated the flow of forces within a solid block of homogeneous substance, which is exposed to 'bite forces' that are balanced by supports similar to the origins of the mandibular adductor muscles. We generated a form which can be (and has been) compared with the actual shape of vertebrate skulls. Our 'generated form' comprises not only the compression- and deformation-resistent skeletal, but also the tension-creating or tension-sustaining soft parts. The skeletal structure so created reflects the functional necessities to be fulfilled by the skull.

Biting by living animals is done regularly on parts of the toothrow alone, or on the tip of the beak. In spite of this, the loads on our models are applied simultaneously along the entire tooth row, in the direction of the tooth roots. Experience has shown that the addition of simultaneously acting bite forces does not change the patterns of stress flows in principle, but rather yields a more complete information. The assumed direction of the bite forces along the tooth roots admittedly is hypthetical, based on the anchoring of the teeth to the jaws, but in agreement with available empirical data (e.g. WITZEL et al. 1998 ; JAKOWSKI \& WITZEL in press).

With only few a-priori-conditions (existence of a nasal cavity, two orbits, and a braincase), and the position and shape of the dental arcade as the independent variable, we have computed the stress flow within an otherwise unstructured 'volume' representing the entire skull (in reptiles), or the skull between the tip of the snout and the walls of the braincase (in mammals). If the general form of the skull, that is its relation between length, height and width are given, the stress flow depends first on the shape and form of the tooth row, second on its position in relation to the braincase, and third from the size of the braincase. Length, height and width defined in our analysis the dimensions of the 'mantle volume' or three-dimensional envelop around the volume provided for the stress flow. We feel justified in defining the 'volume' à priori, because quite convincing arguments have been proposed by zoologists and paleontologists that outline the selective values of the general shapes of the heads in the sense of 'biological roles' (following BOCK \& V. WAHLERT, 1965).

Nobody really doubts that long, slender jaws are well suited for catching swift-moving fishes, or that a low, though wider skull is of advantage for a crocodile that approaches drinking antilopes in the water (as an example, see JORDANSKI, 1973). The shorter jaws and the higher skull in sauropod dinosaurs and iguanids is evidently suited for chewing the rather tough, but not moving vegetable matter the animals are eating, the high skulls of carnosaurs evidently can sustain the enormous bite forces exerted on the huge teeth (RAYFIELD, 2001), and the jaw apparatus of primates is perfect for mastication of tough vegetable material, that is portionized by the hands. The shortness of the jaws makes favourable relations between force and load arms, and the speed of closing extremely long jaws is replaced by a highly developed neuromuscular control system.

After removing all finite elements loaded by less than a threshold value, we arrived at shapes which are remarkably similar to the skull of that primate, or the reptile, from which we have taken the proportions of the dental arcade and the general outline of the investigated skull model. This stage of the analysis, however, could not be realised for the present study, because of limitations in time and funding.

Text-fig. 1. a Heads of two crocodiles. Left: $C$. niloticus with head lifted above surface, right: Osteolamnus with head in lowered position. In both cases, prey objects are between the teeth. The weights of the heads plus the weights of the captured prey are acting downward (applied at the centre of mass of the head, or the prey, respectively). Weight force of the object between teeth and of the head itself are combined to one (assumed) downward directed force, which is balanced by the pull of neck muscles. These forces form the resultant Ro, which pushes against the occipital condyles. Note the variable direction of Ro.

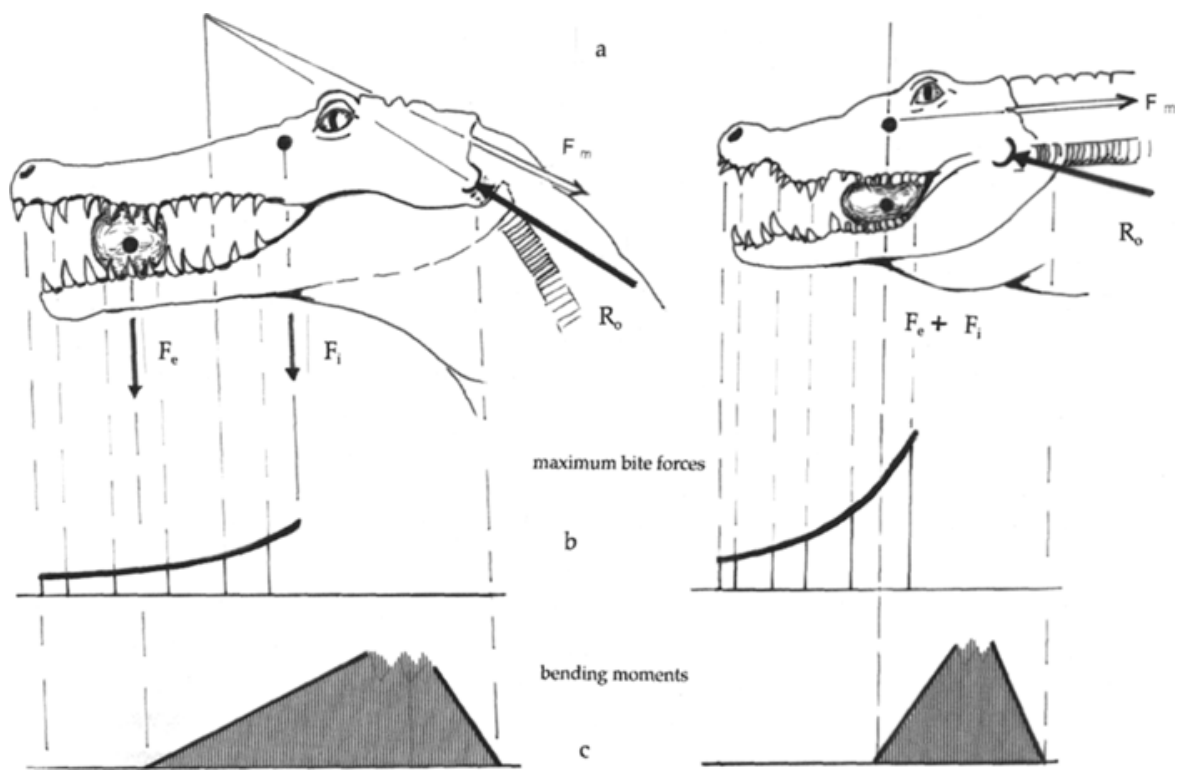

b Maximum bite forces along the jaws. In Osteolamnus the bite forces have shorter load arms, therefore the bite forces are greater, and increase at a steeper angle than in C.n. Maximum bending moments occur at the the adductor muscles and are not shown. The bite moments produced in both crocodiles are assumed to be the same. $\mathbf{c}$ bending moments evoked by biting on the objects shown in $\mathbf{a}$. 


\section{Results}

\section{Crocodile; biostatic principles; bite forces}

The skulls of crocodiles are characterised by the length of the tooth-bearing section in relation to the 'neurocranium', low height and variable width. The adductors of the mandible have short lever arms, which leads to a very rapid movement of the jaws in snapping. The longer the jaws, the greater the speed of their most anterior sections.

Bite forces applied to the anterior teeth (text-fig. 1) can not assume impressive magnitudes (because of the short force and long load arms), but evoke bending moments along the entire length of the jaw, which increase linearly. Their maximum is reached where the adductor muscles cross the elongation of the tooth rows (text-fig. 1).

While in most other reptiles and mammals the insertions of the major mandibular adductors are behind the eyes, the uncommonly long-snouted crocodiles possess a speciality: the adductor muscles are extending forward well in front of the eyes on the dorsal side of the palate, and within the hollow mandible. This arrangement is comparable to what is called in engineering sciences a 'tension chord'. In this case, it is an active structure, which comes into action as soon as the jaws are exposed to load. The same muscles which adduct the mandible so lead to a considerable reduction of the bending moments along the bony structures by taking over a substantial

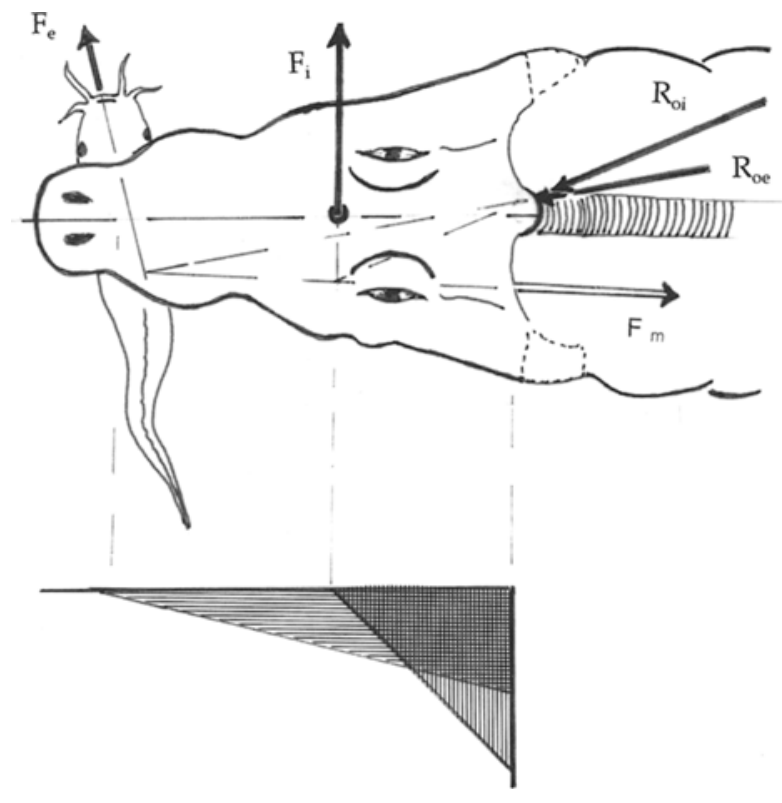

Text-fig. 2. Crocodile head in top view, showing the effect of laterally directed forces on the resultant force Ro. In rapid sidewards snapping, mass inertia (Fi) resists the movement of the head, and a moving prey may also pull the snout to the side with the force Fe. Neck muscles are activated to maintain equilibrium at the occipital condyle, which is under the influence of the resultant force Roi or Roe, respectively. The exact direction of Ro of course depends on the forces Fe or Fi, and on the insertion of the active neck muscles, which are assumed here in a schematic way. part or all of the tensile stresses that occur close to the tooth rows. From the origins of muscles rearward, bending moments decrease to zero at the mandibular joint. The rearward displaced position of the latter (text-fig. 3) is a means to keep the (biologically worthless) joint forces low (GANS, 1961, 1966, 1969 ) in comparison to the (biologically most important) tooth forces.

Bite forces applied to the posterior teeth of course can assume greater values, because the product of maximal muscle force times lever arms of the muscles is the same as in anterior biting, where the load arms are longer. Biting on the posterior teeth does not evoke considerable bending moments, nor stresses at all in the more anterior parts of the jaw. The posteriorly increasing bite forces are reflected in the more slender form of the sometimes (Crocodilus cataphractus, Thomistoma, Gavialis) needle-sharp anterior teeth and the evidently stronger, peglike, or even blunt 'durophagous' (Osteolamnus) posterior teeth.

Bending moments lead to compression along the dorsal contour of the skull and to tension along its ventral surface (text-fig. 1, also text-fig. 4, 5). In the mandible, this force distribution is, of course, inverted. The flow of compressive forces in the skull concentrates along the median plane, provided that muscle insertions are distributed symmetrically on both sides. If muscle insertions are concentrated on the lateral sides alone, however, the force flow splits and requires supports far away from the midline. This can be seen in the mandible, the halves of which therefore need only a part of the bending strength of the skull (see also discussion). For our purpose, it can be taken as an à priori condition dictated by the vertebrate Bauplan.

Anyhow, concentration of compressive forces near the median plane leads, on the basis of causal morphogenesis alone (in the sense of PAUWELS, 1960) to a strengthening of the elements that form the dorsal contour or simply the skull roof, formed by premaxilla, nasal, lacrimal, prefrontal, frontal, postfrontal, squamosum, and parietal bones (text-fig. 1, see also text-figs. 4,5 ).

On the ventral side of the upper jaw, tensile forces occur. As mentioned above, in the crocodiles these tensile forces are largely taken over by the adductor muscles (text-fig. 3). Usually, tensile forces lead to the formation of collageneous fibres and their orientation along these forces. Considerable amounts of collagenous fibre material have been found at the appropriate places in the garpike Lepisosteus (ROSSMANN, oral comm.) and in the bull shark Heterodontus (NoBILING, 1972). There is no doubt that it can be found in other animals as well, as soon as attention is placed on it. Under yet not fully known conditions, collagenous material can be replaced by bone, or occur in combination with bone. Compact bone substance possesses greater strength against tension than collagenous material (AMTMANN, 1971). In fact, there exists (in crocodiles and in mammals) a bony plate in the form of the palate, and in crocodiles, but not in mammals, the pterygoid flange which covers the oral cavity and separates it completely from the air passage. As will be detailed later, saurischian dinosaurs and lizard-like reptiles also possess structures to carry tensile forces at the ventral side of the skull along the dental arcade. These ele- 

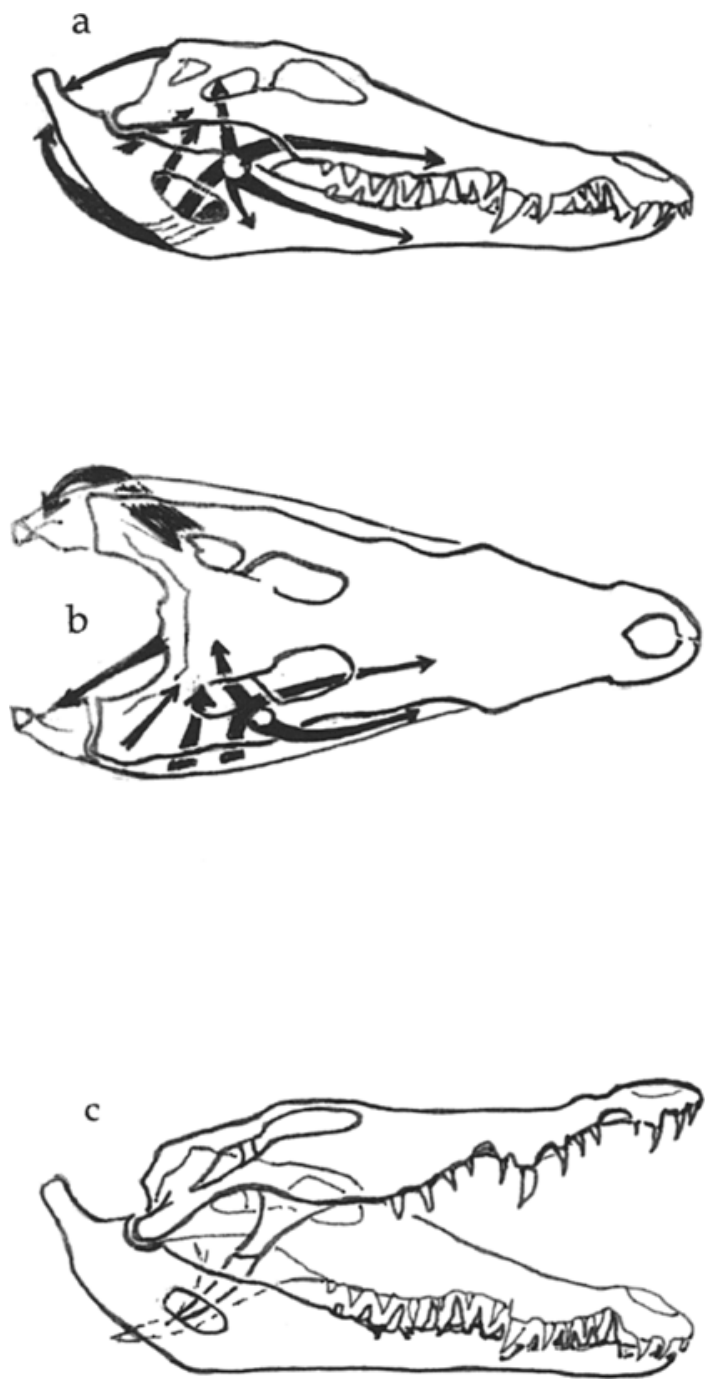

Text-fig. 3. Schematic representation of the adductor muscles of the jaws in a crocodile, after Schumacher 1973. a side view, b top view. Note the fibres of the $\mathrm{m}$. pterygoideus anterior, as well as the $\mathrm{m}$. intramandibularis, both acting as a tension chord to reduce the bending moments in the long, slender jaws. $\mathbf{c}$ side view to show the pterygoid flanges, that keep distance between the halfs of the mandible when the jaws are closed.

ments are not fused in the middle, and must not be in order to fulfil the postulated function.

Bending strength of a 'beam' (like the elongate skull) increases with its height (= extension perpendicular to the force arm) according to the formula for the resistance offered to bending $\mathrm{I}=\int \mathrm{y}{ }^{2 *} \mathrm{dA}$. Therefore, height of the skull, or the distance between its ventral and dorsal contour increases its strength. The downward curved pterygoid flanges in crocodile skulls therefore can be understood as a means to increase bending strength at a place, where the bending stresses reach their maximum. In addition, these pterygoid flanges serve as hypomochlia of tension-producing muscles (text-fig. 3).

Stresses flow around, or circumvent gaps in the skull which are assumed a priori like the eye openings, or the nasal opening. In both cases, under invariable loading conditions there may appear stress concentrations at both sides of the hole, seen in the direction of stress flow (text-fig. 6 ). These concentrations lead to the reinforcement of the respective bony margins. If the forces change in direction, these stress concentrations occur, and reinforcements must be available, in various directions, with the effect, that the openings get a walllike periphery.

Another important sort of stressing, to which the jaws are regularly exposed, is biting on one side alone (text-fig. 5 and text-fig. $7 \mathrm{a}, \mathrm{b}$ ). In addition, many crocodiles use to perform spinning movements about their longitudinal axis, in order to tear apart the bodies of prey animals. One-sided biting as well as spinning create torsion about the longitudinal axis of the snout anterior to the eyes. The sizes of the torsional moments depend not only on the tooth forces, but as well on half the width of the tooth row (text-fig. 7a). That means, torsion reaches its greatest values near the posterior end of the tooth rows, where bite forces are greatest and lever arms longest. Narrow, slender jaws (fish-catching crocodiles) are exposed to lower torsion than relatively short and wide ones (alligators, Osteolamnus). Behind the eyes, however, the circle of forces is closed through the adductor muscles at the lateral sides of the tooth row. This leads to reversed torsion in the posterior skull, and so to a compensation or at least a reduction of rotational stresses (text-fig. $7 b$ ).

The direction of the torsional stresses is perpendicular to those discussed above. Torsional stresses assume their greatest values far away from the torsional axis. That means in our case: the wider and higher the upper jaw, the greater its torsional resistence, following the formula :

$$
\mathrm{T}=\int \mathrm{r}^{2} * \mathrm{dA}
$$

where $T$ is equivalent torsional strength, $r$ the distance of the bony wall from the centre of gravity of the cross section, $\mathrm{dA}$ a small portion of the bony wall of the structure.

At many places, bending and torsional stresses combine to unpredictably complex patterns of resultants, which can hardly be estimated without calculations by FEM. The beam shown in text-fig. 8 is a simple model of a long snout anterior to the eyes, loaded by forces which represent the tooth forces in unilateral biting. Text-fig 9 illustrates compressive and tensile stressess which occur under the influence of these bite forces. Torsional stresses, if applied to either the right or the left side, clearly favour the development of uninterrupted walls of a hollow, tube-like snout, as shown in text-fig. $10 \mathrm{~d}$. For comparison, the pure compressive stress, as evoked without torsion in symmetrical, or bilateral biting (text-fig. $10 \mathrm{c}$ ) is concentrated on the lateral and dorsal sides alone. Great torsional strength is needed particularly in the posterior part, shortly in front of the adductor muscles. In dinosaurs and lacertilia, the antorbital and the postorbital margins have exactly the fitting orientation, as will be detailed below.

An interesting item is the relation between the lever arm of the torsional moment (that is width of the tooth row) and the torsional strength of the upper jaw, that are defined by the above-mentioned formula. In profiles having elliptical outlines, this means that torsional strength exceeds torsional moments (text-fig. $7 \mathrm{c}$ ). 


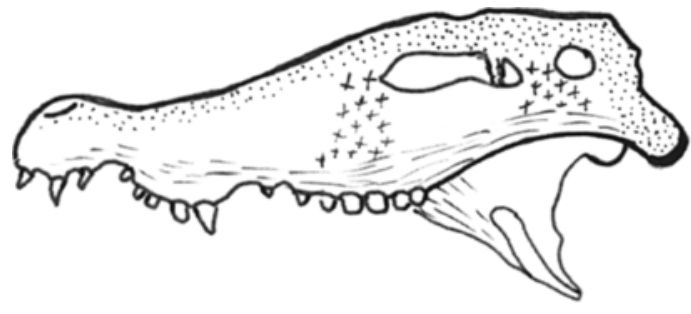

a

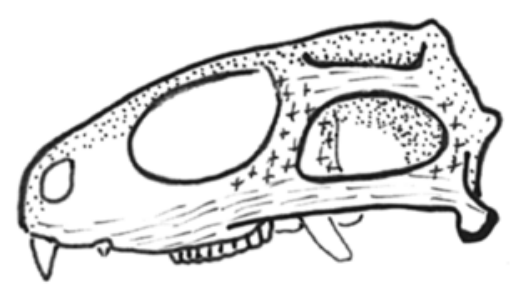

b
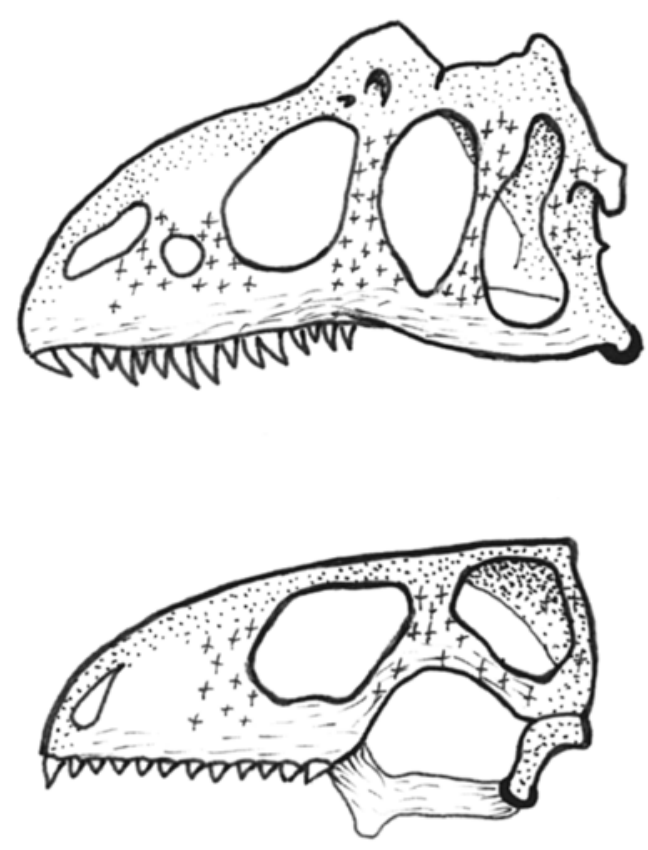

d

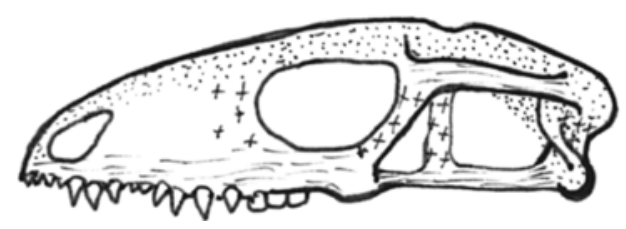

e

Text-fig. 4. Reptilian skulls in side view, when loaded during biting like in Fig. 1. The stress concentrations at the dorsal and the ventral sides are marked, as well as the props to keep distance. (.....) compression, (---) tension, $(++++)$ distance elements a Osteolamnus, b Sphenodon, c Allosaurus, d Iguana, e Tupinambis.

\section{Support of the head}

In the crocodile shown in text-fig. 1, the weight of the head needs to be balanced by the nuchal muscles at the occipital joint. The resultant force Ro that acts on the occipital condyle is directed forward-upward. A great distance between the condyle and the dorsal contour of the skull yields long lever arms for the muscles and therefore keeps down the energy-expenditure. The downward-directed weight force can be increased by some chunk of food, or by a prey captured and lifted from the ground or above the surface of water. A lowering of the head to the level of the most caudal cervical vertebrae leads to a swing of the resultant force Ro toward the longitudinal axis of the jaws. In both cases, the joint resultant Ro requires a structural element that extends from the condyle forward-upward towards the skull roof. This structure exists in the form of the braincase.

Only if the crocodile pulls its head downward against a resistance (like in the attempt to drawn a drinking antilope), the ventral muscles of the neck need to be activated, and the occipital resultant Ro may assume a direction forward-downward.

As the FE-models show, the stresses evoked inside a solid body by a force concentrated on a very small area (for instance the tooth forces in text-figs. 9, or 10) spread and disappear at surprisingly short distances from their point of application. In the case of our resultant force Ro, concentrated on the occipital condyle, it either passes on a short way towards the skull roof, or forward - if Ro is directed downward. As a matter of fact, all reptilian skulls have a marked accumulation of bone material to resist the stress concentration on the occipital condyle. These bony masses extend in part upwards around the foramen magnum towards the skull roof, forming the braincase, and the other part forwards and slightly downward in the form of the basioccipital establishing connections to the otic capsule and the pterygoid.

The neck muscles have extended insertions on the head, so that the stresses created by them are distributed over large areas and so do not lead to obvious stress concentrations.

Great external forces occur also in the plane of the dental arcade (text-fig. 2). Loads of this sort occur in catching prey that moves in relation to the predator, or in snapping sideways (created by inertia), or by tearing objects (prey) apart. In any case, whether the active movement of the head is caused, or a passive movement of the head is counteracted, the lateral neck muscles are active. Bending moments in this plane reach their maximum at the rearmost parts of the skull, where the neck muscles have their insertions. Moments of external forces and of muscle forces must be in balance at the occipital condyle. The resultant Ro now is directed forward with a pronounced deviation from the long axis of the head in either of the lateral directions. This concentrated application of forces requires again bone strength and an accumulation of much bone material in the occipital part of the skull, especially at both sides of the occipital condyle. In fact, the otic capsule or diverse lateral expansions of occipital elements fulfil this function (text-fig. 12).

Like in lateral view, one margin of the skull (not the jaw alone) is extended (text-figs. 2, 5), while the corresponding compressive stresses occur along the midline. The flow of tensile forces concentrates on the most lateral margins. Therefore, a continuous, long bony element must exist on either side of 


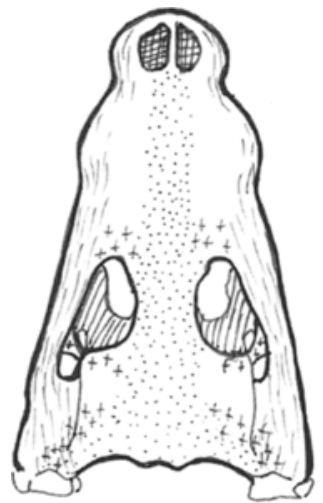

a

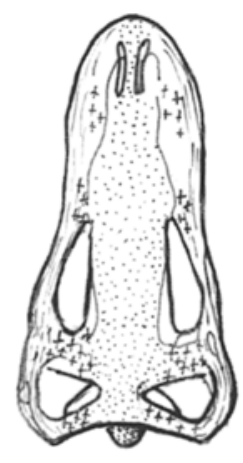

d

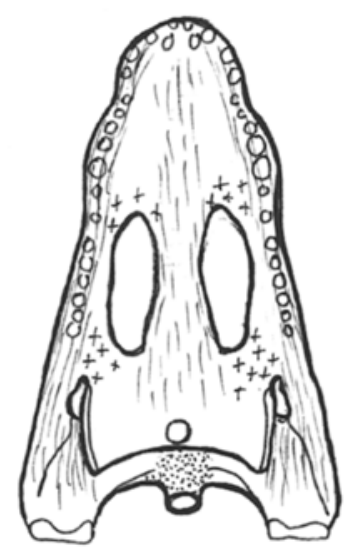

f

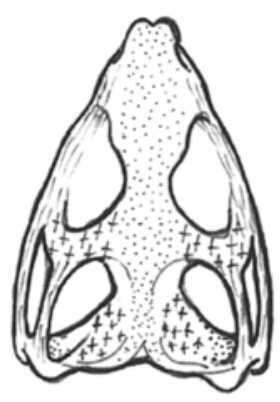

b

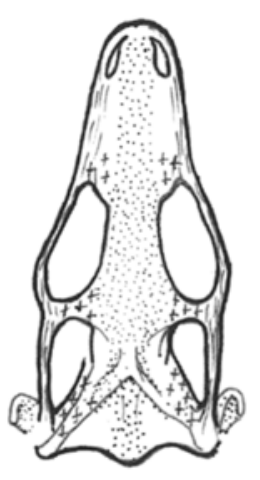

e

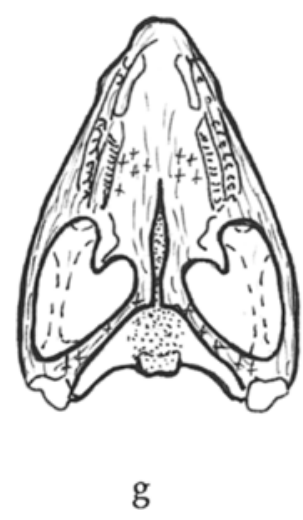

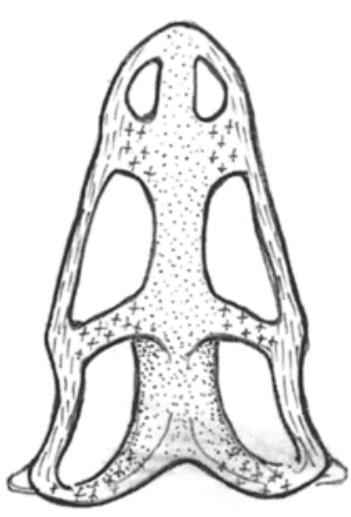

C
Text-fig. 5. Reptile skulls seen from on top (a-d) and from below (d-g) with stresses that occur in sidewards movements. Superimposure of stresses is of course to be expected. a and $\mathbf{f}$ Osteolamnus, $\mathbf{b}$ and $\mathbf{g}$ Sphenodon, $\mathbf{c}$ and $\mathbf{h}$ Iguana, d Allosaurus, e Tupinambis. the skull. In the lower jaw, the right or left mandibular corpus is the only existing structure. In the skull, the jugal arches are the structures which sustain the tensile stresses. The same elements, if in low positions (like in crocodiles, or in carnivorous mammals) can also take over the tensile forces evoked by biting in side view (text-figs 4,5 ). The long anterior $\mathrm{m}$. pterygoideus of the crocodiles doubtlessly reduces the tensile forces on the bones - provided that it is active (which is not necessary for movements in this plane). Structures to resist compressive stresses are the above mentioned dorsal elements of the skull roof, and on the lower surface, the maxillar, palatinum and pterygoid bones, that is the pillar-shaped roof of the oral cavity. The compressive stresses eventually converge on the occiput and in the condyle. The farther away the stretched side from the midline, the smaller the stresses. Between the lateral contour and the midline, areas of zero stress may occur. This in fact is the place where the orbits and the upper temporal opening are located on the dorsal side, and the parapalatinal gaps on the ventral side. However, constructional elements are necessary to maintain the distance between tension- and compression-bearing structures. These are dorsally the postfrontal and the squamosum, ventrally the pterygoid and ectopterygoid. 


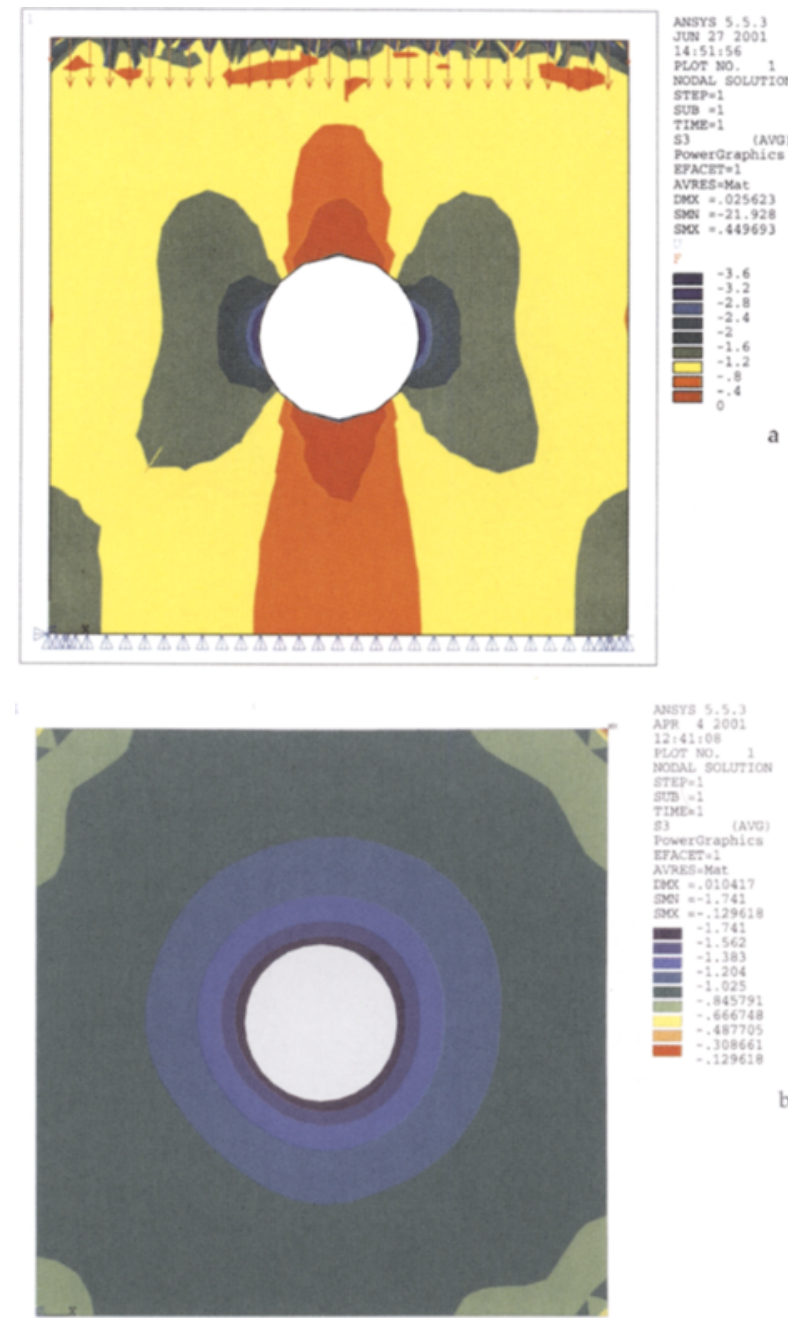

Text-fig. 6. FE-model of a plate with a hole, compressed by a force in vertical direction against its support. Note the stress concentrations at both sides of the hole, and the reduction of the stresses above and below the hole. This indicates the possibility to remove material by opening a slit parallel to the forces. b If forces are applied at right angles to the first pair of forces, high stresses occur around the hole. They require a reinforcement set at $90^{\circ}$ to the most highly stressed fields in a. Loads in varying directions therefore require a ring-like reinforcement around the hole.

A somewhat intriguing structure in crocodile skulls (and as well in Iguana ) may well find an explanation on this basis: the lateral flanges of the pterygoid form a joint-like contact to the medial surfaces of the mandibular bodies. This makes sense if the situation in sideward-directed tearing is considered: like the distance between the (compressed) midline and the (stretched) most lateral toothrows and jugal arches so must be maintained the distance between the right and left halfes of the mandible. This can be accomplished by the pterygoid flanges, which are inserted between them when the jaws are closed (see also JORDANSKI, 1973).

\section{Lepidosauria and (saurischian) Dinosaurs}

All skulls to follow are characterised in contrast to those of the crocodiles by their considerable height in relation to length, two separated bony nasal openings of great width, their large orbital and upper postorbital openings, a delimited toothrow to recieve bite forces, and an 'incomplete' palate. (The obvious antorbital openings are not present in all, particularly smaller, skulls and will be delt with below.) The mandibular joint in all forms is shifted rearward and laterally, though not to the same extent as in crocodiles, but similarly suited to keeping low the joint forces. Mobility of the upper jaw apparently does not exist (Carroll, 1969, Starck 1979 a). Sphenodon and the dinosaurs possess two jugal arches, the iguanids only one and the missing direct connection between the upper tooth row and the mandibular joint or the quadrate is replaced by a strong ligament and a bony bar connecting the quadrate between a point close to the mandibular joint and running medially and anteriorly towards the pterygoid, which is part of the oral roof (text-fig. 10).

$$
\left.\mathrm{I}=\int \mathrm{y}^{2} * \mathrm{~d} \mathrm{~A}\right)
$$

(where $\mathrm{I}$ is resistance against bending, $\mathrm{y}$ the distance from the centre of gravity of the cross section, and $\mathrm{dA}$ a small portion of the bony structure)

In side view (text-fig. 4), bending moments in the skull are created by the bite forces exerted against the upper teeth. In agreement with the formula that describes bending strength, the height of the skull in Tupinambis, Iguana, Allosaurus and Albertosaurus (and of the premaxilla in the sauropods Camarosaurus and Brachiosaurus) increases from its most anterior point rearward following a square root function. Outlines like this are very common among reptiles, and can also be found in the premaxilla of mammals (PREUSCHOFT et al., 1986). The most anterior part of the skull resembles, in a rough approximation, a body of equal strength against the bite forces. The main part of the snout, however, is comparable to a tube (as in crocodiles) or a framework (as in lepidosauria and in dinosaurs). The compressive stresses concentrate along the contour line of the skull in the internasal and the interorbital bar. In Camarosaurus and Brachiosaurus the premaxilla is propped by a slender, bowed rod against the posterior part of the skull roof. This prop is formed by the premaxillar and nasal bones and follows in its outline the same square-root function like in the other forms (text-fig. 4).

Behind the orbits, the stress flow is divided: A first flow runs along the median contour, including the frontal and parietal as well as the braincase to surround the upper temporal opening on its medial side.

A second flow of forces follows a more lateral pillar, running behind the orbits and lateral to the upper temporal opening to the quadrate, where the skull finds its posterior support, and the circle of forces is closed. In the parapsid iguanids this bony element (postorbital, squamosum) forms the shortest connection from skull roof to the quadrate, while in the diapsid skulls it forms a rather sharp angle to meet a transverse extension from the parietal behind the upper temporal opening and bend downward to reach the quadrate plus quadratojugal. The sharp angle at the rear margin of the upper temporal fossa can easily be explained by the fact that strong adductors take their 


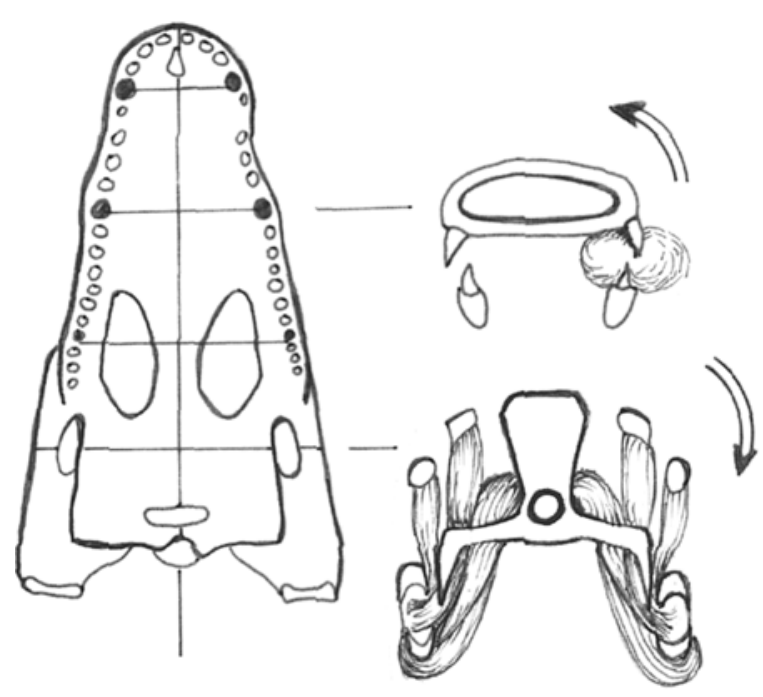

a $\mathrm{b}$

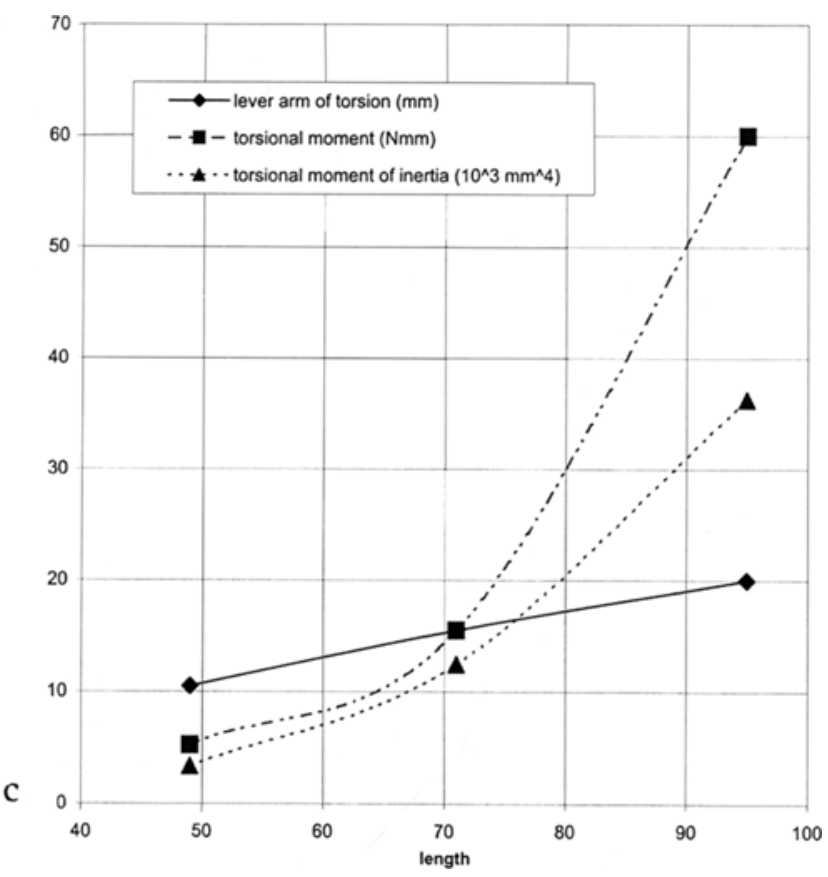

Text-fig. 7. a Caiman skull seen from below, showing the torsional effect of unilateral biting. In addition, bite forces are greater on the more posterior teeth. b Two transverse sections through a crocodile skull, to show the torsional effects of unilateral biting. top: torsional moments evoked by unilateral biting in the snout, anterior to the eyes, bottom: transverse section behind the eyes, through the adductor muscles. Torsion changes its sign. $\mathbf{c}$ Plot of relevant variables (vertical) against length of the dental arcade (horizontal). All values are relative. Lever arms are $1 / 2$ of the width of the tooth row. Torsional moments are calculated under consideration of the rearwardly increasing bite forces, torsional strength of the upper jaw is approximated by an elliptical tube according to the formula:

$I_{t}=\pi n^{3}\left(b_{1}{ }^{4}-b_{2}{ }^{4} / n^{2}+1\right.$, where $a$ and $b$ are the diameters of the tube and $n$ is the proportion $a_{1} / b_{1}=a_{2} / b_{2}$. Note that the strength values are $10^{3}$ times those in the other graphs.

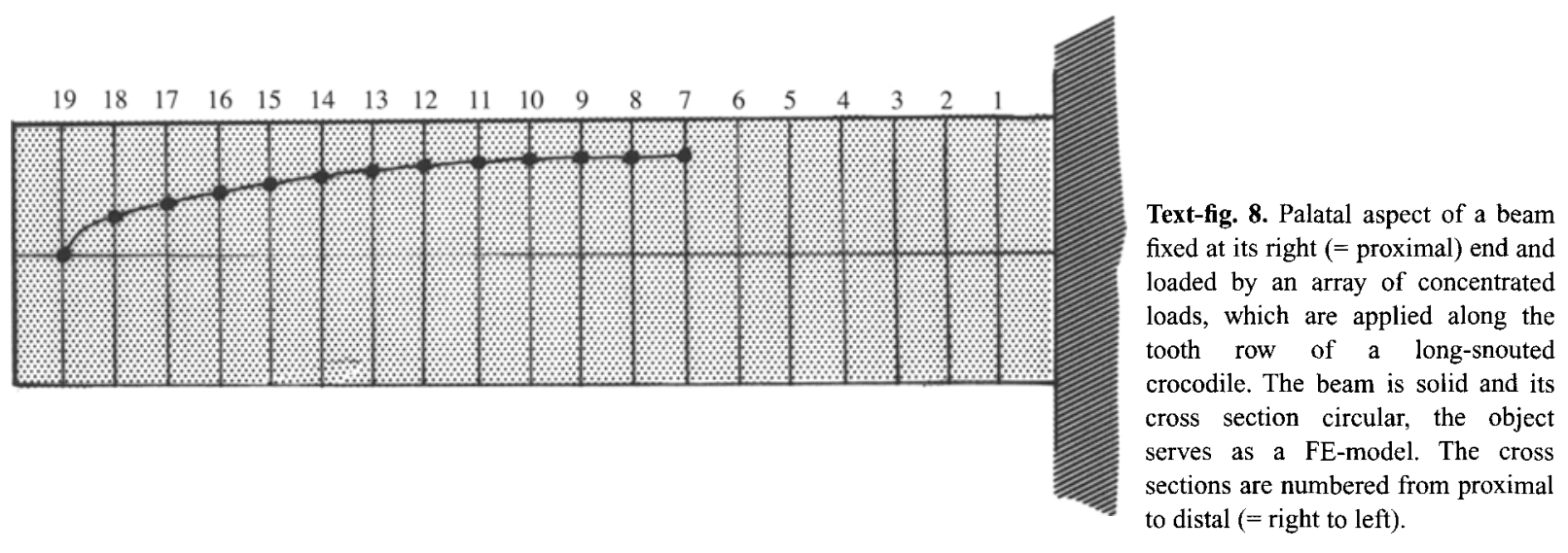

insertion from this area (text-figs. 4, 5 a-d). Seen from behind, the elements mentioned up to here form a more or less steep vault from one mandibular joint to the other, tied in their middle, lateral to the occipital condyle, by a lateral processes of the basioccipital, or the otic capsule (text-fig. 12).

The occipital end of the tooth row, where the greatest bite forces can be produced, is propped against the posterior skull by a postorbital bar in both Iguanids and in Sphenodon., but in the dinosaurs this brace is antorbital, consisting of other elements, but fulfilling the same mechanical task (text-fig. 4).

The tensile stresses at the lower margin of the skull follow the continuous chain of bony structures, premaxilla, max- illa including the 'incomplete' roof of the oral cavity formed by the palatine and the pterygoid (text-figs. 4 and $5 \mathrm{e}-\mathrm{g}$ ). The circle of forces is closed in the diapsids by lower jugal arches which are connected to the quadrate and quadratojugal bones. The lower jugal arch being absent in the parapsid Iguanids, its function is fulfilled by a well-developed ligament. In addition, there exists, in elongation of the oral roof, a robust pterygoid. At the occipital part of the tooth rows, where the tensile stresses reach their maximum, the bony roof of the oral cavity (pterygoid) bends ventrally downward in Iguana and so increases the height of the mechanically resistent structure. It reaches in both iguanids the quadrate close to the mandibular 


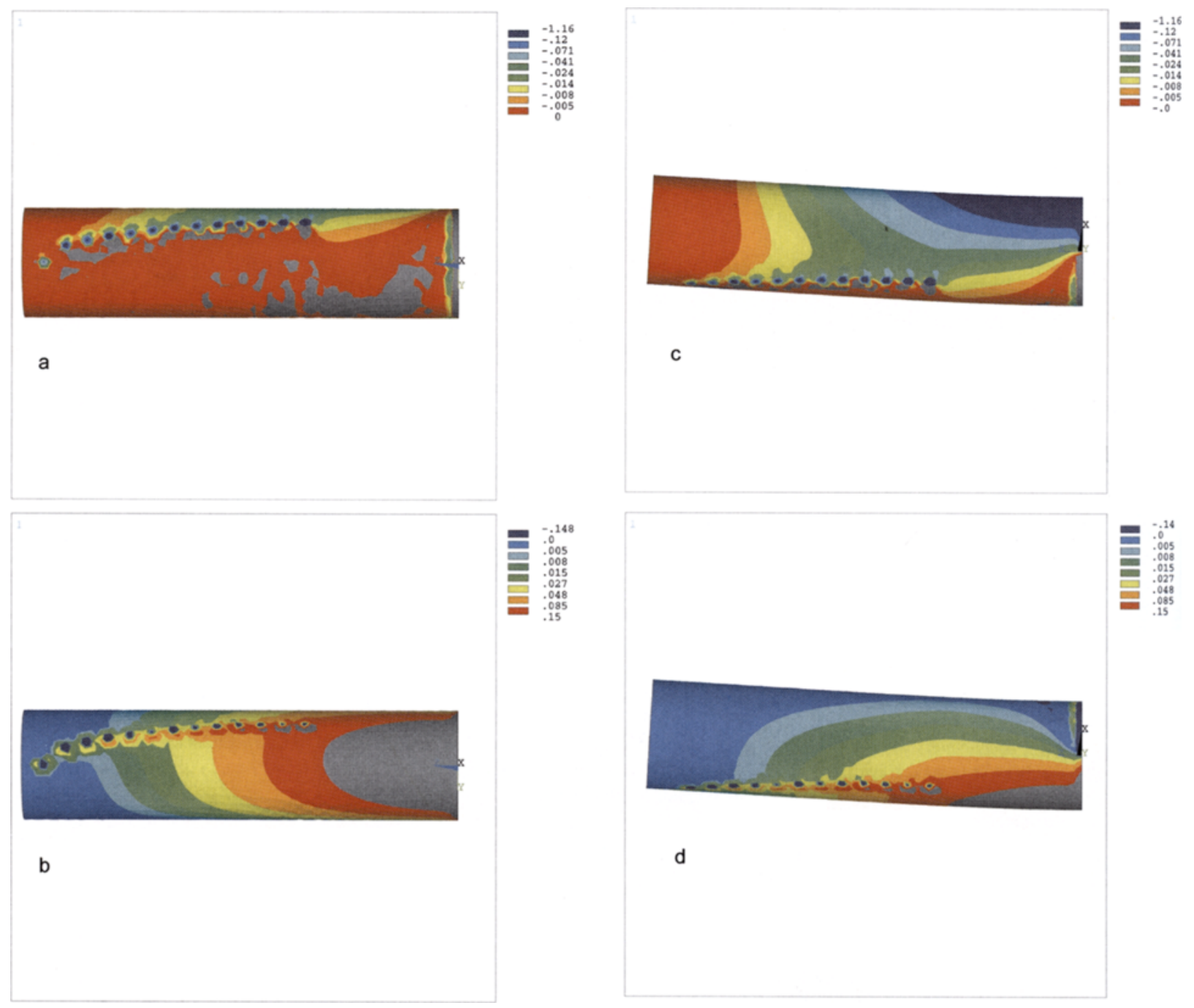

Text-fig. 9. Results of the FE-analysis of the beam in text-fig. 8. a Compressive stresses seen from below, ventral side. No relevant stresses in front of the tooth row, no stresses medial to the tooth row on ventral surface. $\mathbf{b}$ Tensile stresses seen from below. $\mathbf{c}$ compressive stresses in side view, $\mathbf{d}$ tensile stresses in side view. Note the elastic deformation of the beam under the influence of the bite forces. Although the forces are applied to only one side, the stress pattern is not very asymmetrical. On the loaded side, the stresses are exactly as predicted in text-figure 1. All values are relative.

joint. In addition, the posteriorly inclined fibres of the adductor muscles form an 'active' tension chord, and so relief, when contracting, the bony or ligamentous structures. Because of their adducting function, they are active as soon as the jaws are closed and the bending stresses occur.

The 'roof' of the oral cavity is split along its midline into two halfs (text-fig. $5 \mathrm{e}-\mathrm{g}$ ). These halfs are firmly connected to the tooth rows. In this position the elements are also suited to sustain the tensile stresses which occur in horizontal bending of the skull like in text-fig. 2. At their most posterior end, the pterygoid, which establishes the connection to the quadrate, is quite slender in the diapsids (which posses a lower jugal arch), but robust in the parapsids (in which the lower jugal arch is missing). In addition to its carrying longitudinal (tensile) forces as described, it keeps, because of its marked deviation from the median plane, distance between both sides of the skull.

If the distance between dorsal and ventral surface of the skull ('height') is increased, its strength against bending grows by the $2^{\text {nd }}$ power. Consequently, the distance between the compression-bearing dorsal and the tension-bearing ventral margins in which the stresses reach values above the threshold of bone formation, becomes larger. This leads to a wedge of low or zero stresses between them (ROSSMAN, WITZEL \& WELMAN, 2001). These areas of low stresses are correlates of the 'fenestrae' (or gaps) in the skull roof (text-fig. 4).

The highly loaded parts of the skull 'specialise' or 'adapt' to forming strong, clearly separated props. The strength of 'specialised' compressive and tensile structural elements of the skull depends, however, from the distance between them. Therefore structural elements are necessary to maintain the distances. A collapsing of the fenestrated reptile skulls, in which the stress flows are separated, indeed is excluded by props that keep the longitudinal structures at distance. The other possibility, to use a filling with softer material (as shown in PREUSCHOFT et al. 2002) is not realised in the forms considered here. 
While in the small Iguanids and in Sphenodon just the widths of the nasal and the eye openings seem bigger than necessary, the huge skulls of the dinosaurs show such zero-stress openings clearly (text-fig. 4): In the sauropods the nasal apertures are unbelievably wide (WITMER, 2001). One, even two antorbital foramina in series interrupt the continuity of the skull's side wall, and the orbits as well as the lower temporal fossa expand from the dorsal down to the ventral contours. The channels of the nerves seem much wider than necessary, and usually are found at places where stresses are reduced. The maxillary process to the nasals, the antorbital and postorbital bars and finally the occipital wall including the squamosum prevent any reduction of the distance between the compressionbearing upper and the tension-bearing lower longitudinal structures. In addition, the mentioned elements support the origins of the mandibular adductors against being pulled downward towards the teeth.

Both carnosaurs, especially Allosaurus, have conspicuous low 'horns' above and in front of the orbits, formed by the
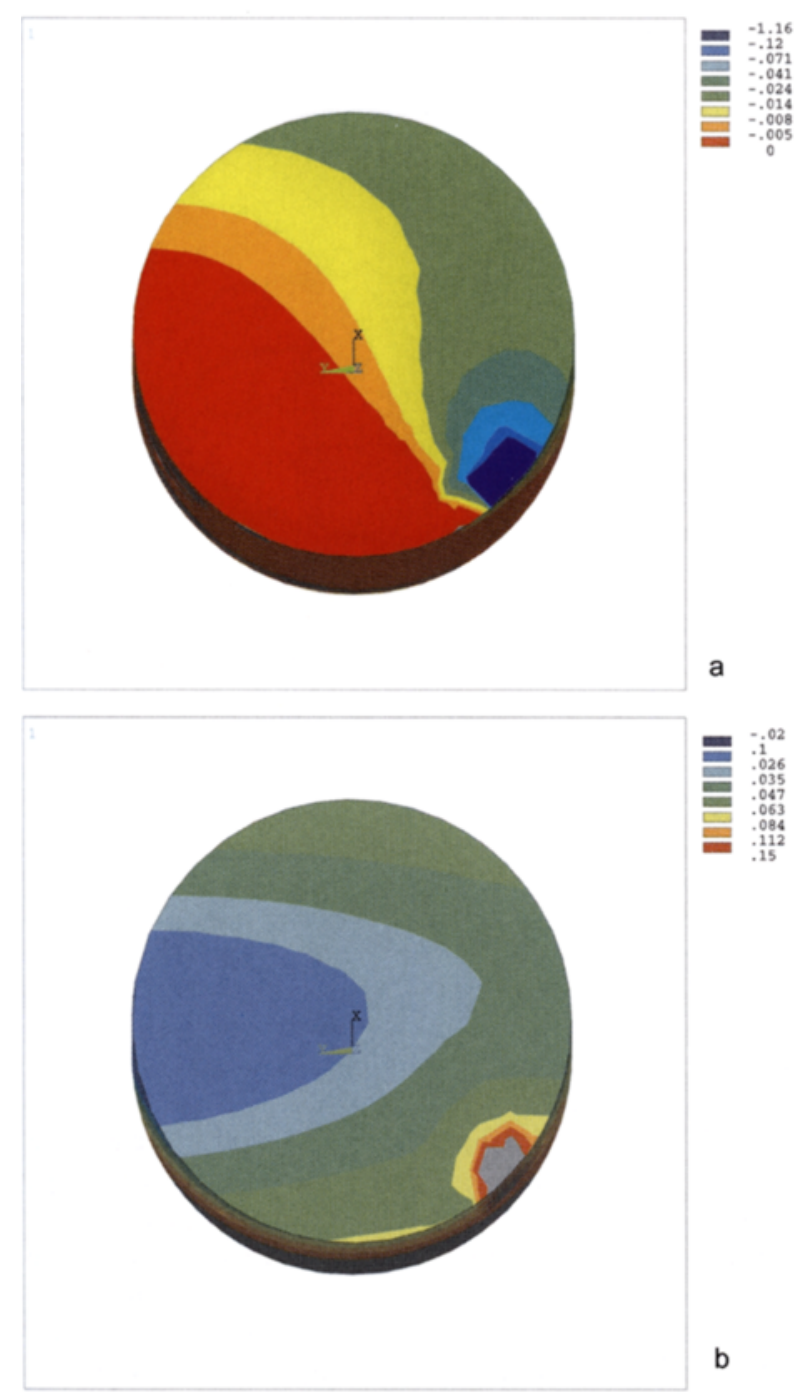

lacrimals. They correspond to stress concentrations that have been found in the FE analysis of Proterosuchus at about the same place (Rossmann, Witzel \& Welman, in press) It seems that these elevations in the skull's outline are reactions of the bone to a concentration of mechanical stress at a point where braces from different directions join. A similar situation can be seen at the lower margin, where the lower jugal arch and the antorbital bar meet.

If seen from below (text-figs. $5 ; 7 \mathrm{f}-\mathrm{h} ; 9 \mathrm{a}, \mathrm{b}$ ), the width of the tooth row shows that biting on one side alone will evoke considerable torsional moments in the section anterior to the orbits. Especially in this region, the bony elements, premaxilla and maxilla form uninterrupted plates in all genera investigated, even in the dinosaurs (text-fig. $4,5 \mathrm{~d}$-e). The torsional stresses and the stress concentrations of the tooth sockets jointly require an accumulation of material. Only at considerable distance from the tooth rows, the stresses converge and are sustained by the strong antorbital and postorbital bars.
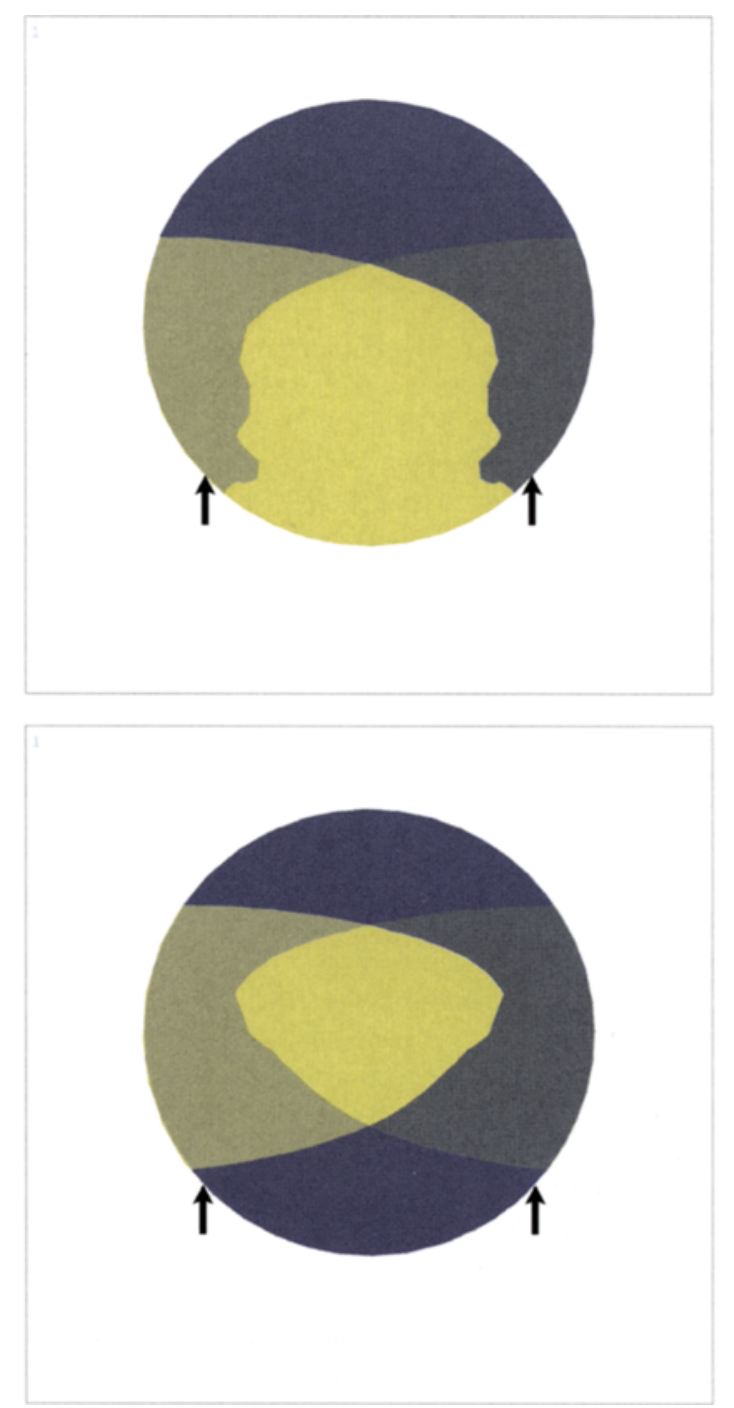

Text-fig. 10. Stress distribution on the cross section number 10 in the model shown in text-fig 8 . a compressive stresses above an arbitrarily set value in unilataeral biting, $\mathbf{b}$ combined stresses in unilateral biting, $\mathbf{c}$ horse-shoe-shaped profile that offers resistence to compression in bilateral biting, $\mathbf{d}$ tube-like profile that offers resistence to a combination of compressive and torsional stresses in unilateral biting on either side. 


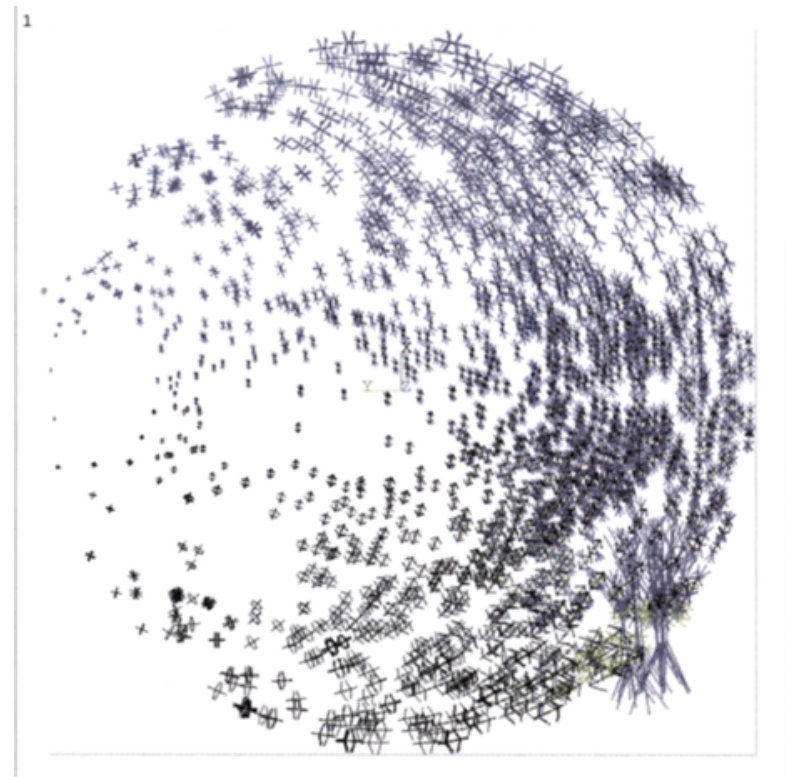

Text-fig. 11. Cross section on level 13 of the model in text-fig. 8, showing the vectors of all forces in combination: compression, tension and torsion. Note the concentration on the right side, where the bite forces are applied, the tension on the palatinal margin and the compression on the right side and especially at the dorsal margin.

Behind the orbits, the circle of forces is closed by the adductor muscles, running downward from the roof of the braincase and from the jugal arches to the mandible (textfig. $7 b$ ). The relative position of the parts to each other are maintained by the lateral extensions of the skull base (parotid process of basioccipital) at the upper, and by the pterygoid at the lower end of the quadrate. On the ventral side of the skull, the described longitudinal element is propped against the tooth row by bony connections in the middle and at the occipital end of the toothrows.

Unilateral biting exposes the oral roof primarily to tensile stresses in transverse direction (text-figs. 10d and 11) which can be sustained by connective tissue, without bone. But the maintenance of the distance between the midline and the lateral margins requires bony braces in transverse direction. These indeed are realised by an anterior (palatine) and a posterior (pterygoid) bony pillar. These elements leave open large gaps between them. These gaps can also be used as internal nose openings or by the vomero-nasal organ.

The stresses, which occur under sideward directed external forces in the plane of the tooth row, are sustained by the most lateral parts of the structure, mainly premaxilla, maxilla and the most lateral jugal arches, no matter whether it is the upper (parapsids) or lower (diapsids). Seen from on top (Fig. 5 a-d), the outline follows a parabolic curve - like the side view in accordance with the formula for bending resistence (see above, crocodile) The compression derived from lateral bending is transmitted along the bony elements of the skull roof and the elements of the oral roof to the skull base.

Compressive stresses converge, like in the crocodile, at the occipital condyle (text-fig. 12). Behind their attachments to the skull base, the pterygoids are much more slender than anterior to this connection, so indicating a stress flow from the pterygoids to the basioccipital.The function of distance-keep- a

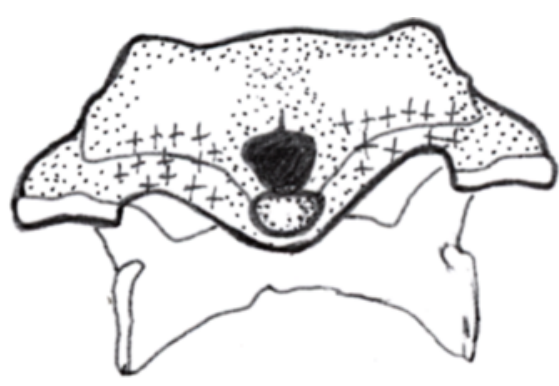

b
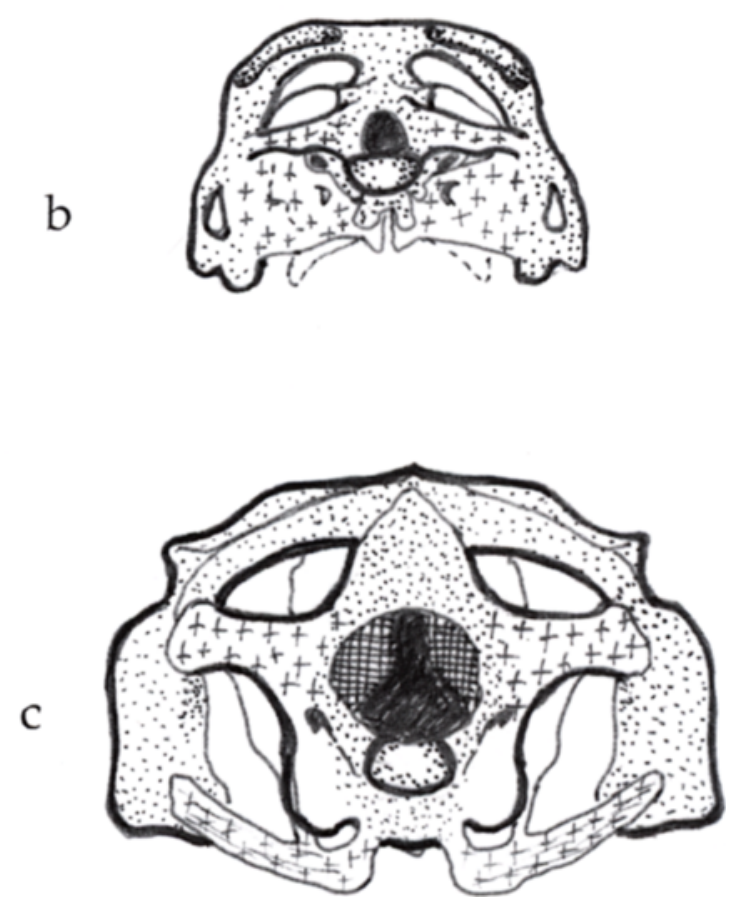

Text-fig. 12. Reptile skulls seen from behind, with major stress bearing parts marked. a Crocodilus, b Sphenodon, c Tupinambis.

ing between the tension- and compression-resisting elements can be fulfilled by a continuous bony plate, like in the skull roof of carnosaurs. The compressive forces in side view are probably especially large in these animals. Tupinambis is intermediate in having a longer maxillary connection reaching the wide nasal bones. The distance can also be maintained by transverse braces, like discussed for the lateral view (see above). Such a structure is realised in Iguana, in the form of antorbital and postorbital bars as well as the massive posterior wall of the skull. Seen from below, the oral roof shows longitudinally orientated gaps between the transverse connections formed by palatinum and pterygoid. Sphenodon, though diapsid, shows a structure very similar to that in Iguana if seen from on top (text-fig. $5 \mathrm{~d}$ ). The narrower skull roof may simply be due to the lesser bending moments in comparison to the carnosaurs and the lesser demands on compressive strength in side view.

Like in the crocodiles, the occipital aspect of the skulls is quite massive and continuous, in spite of the slender structures 
visible in side- and top view. This of course is to be considered as the direct consequence of the force concentration on the occipital condyle. In particular in the large-bodied forms, the condyle is located far away from the skull's dorsal outline, so that the neck muscles have long lever arms. Nevertheless, the varying direction of resultant forces on the condyle (Ro) requires remarkable strength in all directions (text-fig. 1,2).

\section{Mammals, especially Primates and Insectivores.}

In contrast to the above analysed reptilian skulis, which are dominated by their jaw apparatus and often consist mainly of rod-like elements, the skulls of mammals have a rather voluminous and thin-walled braincase, and a nasal capsule. Very often the jaws are less long, but much more robust. Technically speaking, they represent shell-structures. A well-known characteristic of shells is that they distribute stresses over large surfaces and so keep them low. Thin-walled shells offer surprisingly high resistence against forces, but are difficult to analyse without FEM. A rather simple-looking example is found in the skulls of shrews (Soricidae). These small insectivores posses a skull that is tube-like, or more exactly, a slender, hollow, thin-walled cone (text-fig. 13). In its mechanical characteristics, it resembles closely the tube shown and analysed in text-figs. $8,9,10$ and 11 . As can be seen from text-fig. 11, the combined compressive, torsional and tensile stresses concentrate along the periphery of a column, leaving the center free of stress. The appropriate form to sustain these stresses is a hollow tube. The situation is analogous to that in the snout of the crocodiles. However, the soricid skull is supported at its closed occipital end, where the neck muscles insert and the condyles transmit the resultant force Ro on the head. Its shape seems to be given a priori by the relatively large braincase and the huge nasal capsula. At its anterior lower surface, the teeth, that means the points of application of bite forces are located. Their fixation is an interesting example of realisation of engineering principles in biology, but not to be detailed here. Because of its diameter, the 'tube' alone is so strong, that it absorbs all stresses, bending in two planes as well as torsional. As a consequence, the zygomatic arches are not stressed at all and therefore reduced completely.

A different, in some respects the opposite morphology can be seen in hominoid primates. Their skulls resemble an assemblage of at least four 'shells' or 'half-shells': the nasal cavity, the two orbits and the braincase. These shells are connected by again thin-walled, but expanded structural elements, which also possess characteristics of shell structures, often surrounding hollow, 'pneumatized' spaces (PREUSCHOFT \& WITZEL, 2002).

The braincase in all primates, and probably in the mammals throughout, is so large, that the best way to understand it, is its interpretion as a 'shell'-structure in a mechanical sence. DEMEs (1986) has found in an experimental study that the skull base plus side walls in hominoids show the characteristics of shells, with stress-free areas exactly at the points where the cerebral nerves leave the cranial cavity. In our own studies, we replaced the skull cap up to now by a line of supports, following the section made usually in anatomy and pathology to open the braincase. Between the braincase and the upper jaw, there occurred a major stress-bearing area along the premaxilla-maxilla at both sides of the nasal aperture-nasal roof- frontal bone
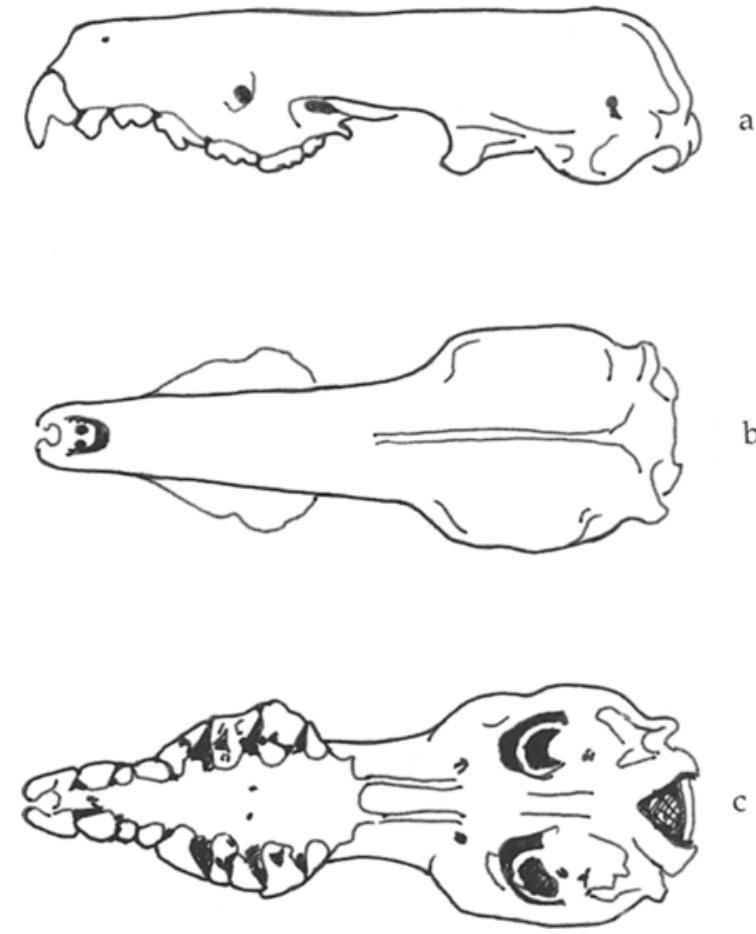

Text-fig. 13. Tube-like skull of a shrew without zygomatic arches, a side view, $\mathbf{b}$ from on top, $\mathbf{d}$ seen from below to show the position of the tooth rows. Redrawn after GoodmAN et al. 2001.

(the 'nasal pillar') and a stress concentration connecting the lateral wall of the maxillary sinus to the lateral margins of the orbits ('zygomatic pillar'), and a less pronounced, more restricted stress concentration at the posterior end of the tooth row in the rear walls of the maxillary sinus ('pterygoid pillar'). The sinuses and a surprising number of morphological details find their counterparts in the stress flows in the FE-models. If we elongate the FE-model used for humans - or if we move an (U-shaped) tooth row forward and diminish at the same time the braincase, stress flows tend towards pathways which resemble closely the shape of other living hominoids, namely the orang-utan and, if the muscle origins are changed in an appropriate way, they come close to the chimpanzee and gorilla (PREUSCHOFT \& WITZEL in press).

The stress concentration lateral to the orbits extends as a narrow strip from the zygomatic bone slightly lateral and upward towards the skull vault. In that study (WITZEL \& PREUSCHOFT 2002), we took this as a first indication of the mechanical reason for the existence of the zygomatic arch, which in mammals (at least in primates) is the only element showing any resemblence to the rod-like bony structures that characterised the reptile skull.

To make our incipient zygomatic arch more similar to the actual shape of that part in a human skull, we took into consideration its realistic topographic and functional relationship to the adductor muscles: The temporal fascia may be seen as a tendon of origin for the masseter, and the swelling of the m.temporalis in the state of contraction tautens the fascia and so exerts an upward pulling force. In anterior view, the fascia above and the $\mathrm{m}$. masseter below the zygomatic arch include a blunt, medially open angle. Therefore the pulling forces trans- 
mitted by them combine to a resultant directed medially. In our model, instead of one resultant, a series of small forces were applied, which together represent the resultant of the force exerted by the $\mathrm{m}$. masseter, pulling downward, and the upward directed tension evoked in the fascia temporalis. By this addition, we changed the position of this stress flow, shifting it downward to its actual and, as we believe, phylogenetically caused position. The narrower the angle, the longer the resultant, that means, the greater the force.

If the situation in a none-human ape is considered (PREuSChOFT, Witzel \& SiCK, 2001), the dependence of the zygomatic arch from the temporal fascia and the masseter comes out clearly. Chimpanzees as well as gorillas possess a narrower braincase than humans do, therefore a temporal fascia which is more medially inclined, and also a narrower mandibular angle than the more laterally curved zygomatic arch. That means, the angle between the tensile forces exerted by the chewing muscles is more acute than in humans. Consequently, the resultant force is much greater, and the zygomatic arch much stronger than in humans. The exact angle (= size of the resultant) depends on the curvature of the cranial vault and the width of the mandibular angle. If these changes are taken into consideration in an individual, characteristic changes in direction and size of the redirectional force become apparent. In side view, the points of application of the masseter force and its size in relation to the pull of the facia may vary. The curvature changes accordingly along the zygomatic arch from its anterior to its posterior root in accordance with the bending moments to which it is exposed. In side view, the points of application of forces vary with the insertions of the temporal and masseter muscles. The curvature in side view and the profile of the zygomatic arch correspond perfectly to the mechanical stresses evoked by bending.

\section{Discussion}

Most considerations about skull shape and skull development traditionally emphasise the homologising of the individual bony elements that build up the skull, and the fenestrations of the reptilian and mammalian skulls.

We propose, however, a different approach, namely to concentrate on the biomechanic conditions, to which the skull is exposed by fulfilling the unquestionable primary function of the jaws, biting, as well as supporting the weight of the head plus additional forces that come from movements of the head against resistence of either inertia, or loads applied from outside. The way, in which external forces act on the animal's body, are the essential factors of behaviour.

The basic divergence between the upper jaw plus neurocranium on one side and lower jaw on the other can not be explained mechanically. It very probably is a matter of the phylogenetic processes which have led to the transformation of the first branchial arcade into the upper and lower jaws, and further to the formation of the viscerocranium (as explained in textbooks of comparative anatomy, like ROMER \& FRICK, 1966, STARCK, 1979).

Our new approach is made possible by a static analysis and is detailed and supported by a modern finite-element-program, which allows the analysis of stress distribution within a three-dimensional, homogenous body under defined load. These stress patterns correspond closely to the realistic shapes of the skulls.

The interpretation of skull shape as a structure which is 'adapted' to sustaining the stresses that occur in fulfilling its function, is most parsimonious.

For meeting the mechanical requirements, or, more precisely, for sustaining the stresses evoked by biting, twisting, or sideways action of the skull, only one condition must be fulfilled: existence of sufficient amounts of bone material at those places where it is needed. Reduction of bone substance naturally saves weight, and the best way to make use of the strength inherent to bony rods is to place them in the direction of the forces that occur locally. It is completely unimportant for survival, from which skeletal element the bone material comes. The anatomically defined elements are not more than remnants of embryonic bone cores, which have fused to fulfil their func- tion. As STROTdREEs (1998) has shown in the marsupial Monodelphis the first bone cores appear at those places, where the highest mechanical stresses occur in the embryonic skull. Growth brings them into contact with one another, and at the lines of contact, sutures are formed. The sutures potentially are week points in the mechanical structure of the definite bony skull, and their stressing is often minimized by orientation of the suture at right angles to the most common forces (see also HERRING \& RAFFERTY, 2000; RAFFERTY \& HERRING, 1999). This does not preclude that sutures can also be transformed to be joints (like in the pig's nose, HERRING 1972), or that force transmission can be secured by interdigitizing of the adjacing elements.

If neither a nasal capsula is assumed a priori, nor a voluminous braincase, there occurs a pattern of stress concentrations that are similar to the trabeculae that constitute the skulls of iguanids, varanids, or some dinosaurs. Our results are in perfect agreement with those obtained by RAYFIELD (2001) on Allosaurus. The often-discussed 'fenestrae' of the reptilian skull so seem to be nothing than the consequence of the concentration of stress flows in long-snouted and small-brained forms. Crocodile skulls are determined to a very large extent by the extremely long tooth row, which extends far in front of the small braincase, and the flatnes of the entire head.

The steep inclination of the brain base in reptiles (STARCK, $1979 \mathrm{~b}$ ) may well have to do more with the static necessity of distributing the joint force Ro than with the size of the eye-balls which have been made responsible for this trait (STARCK 1979 b).

It is an intriguing question whether the nerves just use places that are little stressed to reach the outer body surface, or whether the nerves preexisted and the skull construction had to circumvent the sites of the nerves.

Our results indicate the mechanical relevance of the bony rod-structures in at least three groups of reptiles, and of the shell-structures as well as the zygomatic arch in some insectivores and primates. The important question raised here, is why reptiles tend to built a framework consisting of rods with fenestrations in between, and mammals, in particular primates, tend strongly to thin-walled shell-structures, with only one rod- 
like element, namely the zygomatic arch. It seems that the decisive factor is nothing than the size of the braincase.

If the braincase is large in comparison to the size of the whole skull, the thin-walled, in two planes curved, or vaulted wall of the braincase and the nasal capsula relieve the rods in which the stresses flow in the reptilian-type skull to such an extend that they can disappear, as is the case in shrews. There is, however, one exception, namely, the zygomatic arch.

The morphological characteristics of this element seem to depend mainly on the stresses created by the interplay of $\mathrm{mm}$. temporalis and masseter. In the human skull, a structure at the sides of the braincase (PREUSCHOFT \& WITZEL in press), comparable to the zygomatic arch appears under load, without any manipulation of the model. By a biologically reasonable assumption about the stressing of the zygomatic arch by the masticatory muscles, it separates from the braincase. In the skulls of hominoids, it assumes, under the influence of realistic muscle origins, exactly the form of this structure in the investigated forms (PREUSCHOFT, WITZEL \& SICK, 2001).

The characteristics of skull shape seem to depend on the situation in early ontogenetic development, probably at the time when the jaw apparatus is loaded the first time. The then existing structures channel the stress flows and lead to their reinforcement by causal morphogenetic processes.

\section{Conclusions}

The factors which determine the flow of forces in a solid, homogenous body, and so turn out to be the independent variables of skull shape, seem to be the length and width of the jaw apparatus, as well as its relative position to a large or small nasal capsula and braincase, and the size of the braincase. The arrangement of the adductor muscles is of importance, but investigated in this study only with respect to its static function on the elongated jaws of crocodiles. In addition to these purely 'biomechanical' factors, 'biological' factors, such as the location of the nasal opening, and of the eyes, and the size of the braincase and of the nasal capsule, which are dictated by the mode of living, exert very important influence. Together, these factors decide about the shape of the skull.

Our experience with biomechanical as well as FE-models has shown that once these factors are given, the exact shape of the skull is completely determined and not more than a consequence of the stress flow. It is easy and very plausible to imagine quite convincing selective advantages for the "biological' characteristics (most of them already pinned down in the literature, often confirmed by careful observations of behaviour). We therefore assume that selection attacked at the mentioned 'biological' factors, while the flow of forces, or the size of local stresses dictated the exact shape of the skull in all details. Consequently, no other influences on skull shape must be searched.

Since morphological details can be fully explained as an answer to functional necessities, or, more precisely, to mechanical stress, there is no need for any additional arguments (like weight reduction - which is anyway a general principle in all vertebrate skeletons, or protection of the anterior part of the body or of the sense organs and the brain, or just the relaxed (biological) necessity of an armoured anterior part of the body) to explain their existence. The necessity to provide mechanical stability is the most parsimonious explanation of the skull's shape.

We hope that this paper contributes to the spreading of a new, more functionally-orientated approach to the vertebrate skull at the expense of the largely descriptive, sometimes illogical (the common idea that fenestrations are broken into the cranial wall by expanding muscles is by no means compatible with what we know about the morphogenetic causes for the formation of bone) concentration on fenestrations and the questions which elements are 'primitive', which 'advanced', or which are retained from ancestors or which newly acquired. Morphology, we feel, should be better connected to behavior in order to emphasize the most prominent characteristic of living animals, namely improved potentials to bite and the ability to move the head independent from the mass of the body, and so to react to environment.

\section{References}

AMTMANN, E. (1971): Mechanical stress, functional adaptation and the variation structure of the human femur diaphysis. - Ergebn. Anat Entw,-Gesch. 44(3):

BOCK, W. \& V. WAHLERT (1965): Adaptation and the form-function complex. Evolution 19: 269-299

CARroll, R. L. (1969): Origin of reptiles. - In: Gans, C., Bellairs, A. D'A. \& PARsons, T. S. [eds]: Biology of the Reptilia, Vol. I, Academic Press, London \& New York, 1-44,

GANS ,C. (1961): The feeding mechanism of snakes and ist possible evolution. - Amer. Zool. 1: 217-227

GANS, C. (1966): The function of the retroarticular process in some fossil reptiles. - J. Zool. London, 150: $273-277$

GANS, C. (1969): Comments on inertial feeding. - Copeia 1969 (4) $855-857$

GREGORY, W. K. (1929/1963): Our face, from fish to man. - Hafner Publishing Co., New York, London.

Goodman, S, M., Hutterer, R. \& Ngegueguen, P. R. (2001): a report on the community of shrews (Mammalia, Soricidae) occuring in the Minkébé Forest, Northeastern Gabon. - Mammalian Biology, 66: 22-34

HERRING, S. W. (1972): Sutures: A tool in functional cranial analysis. Acta anat. 83: 222-247
HERRING, S. W. \& RAFFERTY, K. L. (2000): Cranial and facial sutures: functional loading in relation to growth and morphology. - In: DAVIDOVITCH, Z. \& MAH, J. [eds]: Biological mechanisms of tooth eruption, resorption and replacement by implants. Harvard Soc. Adv. Orthodontics, Boston, 269-276

HOFER, H. (1960): Vergleichende Untersuchungen am Schädel von Tupinambis und Varanus mit besonderer Berücksichtigung ihrer Kinetik. - Morph. Jb. 100: 706-746

JAKOWSKI, J. \& WITZEL, U. (in press): Kraftflußlinienanalyse axial belasteter Implantatkörper in der posterioren Maxilla mit Hilfe der Finite-Element-Methode.

JORDANSKI, N. N. (1973): The skull of the crocodilia. - In: GANS , C. \& PARSONS, T. S. [eds]: The Biology of the Reptilia. Vol. 4 Academic Press, London \& New York, 201-262

KUMMER, B. (1972): Biomechanics of bone: Mechanical properties, functional structure, functional adaptation. - In: Y.C. FUNG, N. PERRONE \& M. ANLICKER [eds]: Biomechanics, its Foundation and Objectives. - Prentice Hall, Englewood Cliffs, 237-271

KUMMER, B. (1980): - In: BENNINGHOFF-GOERTTLER: Anatomie des Menschen, Bd. 1, 13. Aufl., Thieme, Stuttgart.

NobILING, G. (1976): Die Biomechanik des Kieferapparates beim Stierkopthai (Heterodontus portusjacksoni $=H$. philippi). Ergebn. Anat. Entw.-Gesch. 52 (6) Springer, Berlin 
Pauwels, F. (1960): Eine neue Theorie über den Einfluss mechanischer Reize auf die Differenzierung der Stützgewebe. $-Z$. Anat Entw.-Gesch. 121: 478-515.

PAuwels, F. (1965): Gesammelte Abhandlungen zur funktionellen Anatomie des Bewegungsapparates. - Springer, Berlin

Preuschoft, H., B. DeMES, M. MeIER \& H. F. BÄr (1985): Die biomechanischen Prinzipien im Oberkiefer von langschnauzigen Wirbeltieren. - Z. Morph. Anthrop., 76: 1-24

Preuschoft, H., B. Demes, M. MeIER \& H. F. BÄr (1986): Les principes mécaniques réalisés dans la machoire supérieure des vertèbres à museau long. - M. SAKKA [ed]: Définition et Origines de l'homme. CNRS, Paris, 177-198

PreuschofT, H., WitTe, H. \& WITZEL, U. (2002): Pneumatized spaces, sinuses and spongy bone in the skulls of primates. Anthrop. Anz. 60 (in press)

Preuschoft, H., Witzel, U. \& Sick (2001): The role of the zygomatic arch for the statics of the skull and its adaptive shape. - $J$. Morphol., 248: 272 (abstract only).

RAYFIELD, E. J. (2001): Functional morphology of the skull of Allosaurus fragilis: a study using the Finite Element Method. - J. Morphology, 248: 274 (abstract only)

RAFFERTY, K. L. \& HERRING, S.W. (1999): Craniofacial sutures: Morphology, growth, and in vivo masticatory strains. - J. Morphol. 242 167-179

ROMER, A. S. \& FRICK, H. (1966) : Vergleichende Anatomie der Wirbeltiere. 2. Aufl. - Parey-Verlag, Berlin

Romer, A. S. \& PARSons, T. S. (1991): Vergl. Anatomie der Wirbeltiere. 5. Aufl. - Parey, Berlin

ROSSMANN, T., WITZEL, U. \& WELMAN, J. (2001): Biomechanics of the skull in Proterosuchus. - Poster, IVM-Meeting, Jena. J. Morphology, 248: 277 (abstract only)
SCHLEBERGER, R. (1990): Weichteilmodellierung am Beispiel einer Gelenkentwicklung. - Habilitationsschrift Bochum

SCHUMACHER, G. H. (1973): The head muscles and hyolaryngeal skeleton of turtles and crocodilians. - In: C. GANS \& T. S. PARSONS [eds] Biology of the reptilia, Vol. 4, Acad. Press, London \& New York, 101-199

STARCK, D. (1979 a): Vergleichende Anatomie der Wirbeltiere Bd. 2 Springer, Heidelberg.

STARCK, D. (1979 b): Cranio-cerebral relations in recent reptiles. - In: Gans, C., NorthCutt, R.G. \& Ulinski, PH. [eds]: Biology of the Reptilia. Vol. 9, Academic Press, London \& New York, 1-38

STROTDREES, E. (1998): Das Chondrocranium von Monodelphis domestica. - Med. Diss. Bochum

SWINTON, W. E. (1970): Dinosaurs. - George Allen \& Unwin, London VERSLUYS, A. (1936): Cranium und Visceralskelett der Reptilien. - In: BOLK, KALLIUS, GÖPPERT \& LUBOSCH [eds]: Vergleichende Anatomie der Wirbeltiere. Bd. IV, Urban \& Schwarzenberg, Berlin \& Wien, 699-808

WITMER, L. M. (2001): Reconstructing the evolutionary history of the nasal apparatus ofd Sauropsida, with special reference to Archosauria. - J. Morphology, 248: 301 (abstract)

Witzel, U. \& PreuschofT, H. (1999): The bony roof of the nose in humans and other primates. - Zoolog. Anz. 238: 103-115

Witzel, U. \& PreuschofT, H. (2002): Function- dependent shape characteristics of the human skull. - Anthrop. Anz. 60 (in press)

WITZEL, U., JACKOWSKI, J. \& JÖHREN, P. (1998): Analyse der Spannugsverteilung im spongiösen Sinus-Augmentat nach sekundärer Implantation mit Hilfe der Methode der finiten Elemente (FEM). Target 1, Straumann, Freiburg, 10-11. 